\title{
Risperidone reduced the risk of relapse in outpatient schizophrenia and schizoaffective disorder
}

\author{
Csernansky JG, Mahmoud R, Brenner R, for The Risperidone-USA-79 Study Group. A comparison of risperidone and \\ haloperidol for the prevention of relapse in patients with schizophrenia. N Engl J Med 2002 Jan 3;346:16-22.
}

\section{QUESTION: In outpatients with schizophrenia or schizoaffective disorder, is risperidone more effective than haloperidol for reducing the risk of relapse?}

\section{Design}

Randomised \{allocation concealed*\}†, blinded \{patients and clinicians $\} \nmid$,* controlled trial with follow up to time of treatment discontinuation (Risperidone-USA-79 Study).

\section{Setting}

40 sites in the US.

\section{Patients}

397 patients who were $18-65$ years of age, had a diagnosis of schizophrenia or schizoaffective disorder according to DSM-IV criteria, had required intensive psychiatric treatment within 24 months before study entry, had received a stable dose of antipsychotic medication for $\geqslant 30$ days before study entry, had resided at the same address for $\geqslant 30$ days before study entry, and were judged clinically stable by the principal investigator. Exclusion criteria included another current $D S M-I V$ Axis I diagnosis and an Axis II diagnosis of borderline personality disorder or antisocial personality disorder. 365 patients (92\%) (mean age $40 \mathrm{y}, 70 \%$ men, 48\% white) were included in the analysis.

\section{Intervention}

Patients were allocated to 1 of 2 groups. Risperidone was increased from $1 \mathrm{mg}$ /day to $4 \mathrm{mg}$ /day on days 1-3 and doses were adjusted in the range of $2 \mathrm{mg} /$ day to 8 $\mathrm{mg} /$ day from day 8 onward. Haloperidol was increased from $2 \mathrm{mg}$ /day to $10 \mathrm{mg}$ /day on days 1-3 and doses were adjusted in the range of $5 \mathrm{mg} /$ day to $20 \mathrm{mg}$ /day from day 8 onward. Lower doses were permitted in rare cases. Antipsychotic medications taken before study entry were gradually reduced during days 1-7 to minimise possible adverse events associated with medication discontinuation.

\section{Main outcome measures \\ Relapse rates and time to first relapse.}

\section{Main results}

Analyses over the 2.2 year period were done on patients who were assessed at least once during treatment, and data for the time to relapse analysis were censored at time of treatment discontinuation. Median duration of treatment was 364 days in the risperidone group $(\mathrm{n}=177)$ and 238 days in the haloperidol group $(\mathrm{n}=188)$. Relapse occurred in 45 patients (25\%) receiving risperidone and in 75 patients (40\%) receiving haloperidol. Risk of relapse was lower in the risperidone group than in the haloperidol group (table).

Risperidone $v$ haloperidol in outpatient schizophrenia and schizoaffective disorder $\doteqdot$

\section{COMMENTARY} Csernansky et al overcomes some of these difficulties. use. would be smaller in clinical practice. possibility that therapeutic advantages are an artefact of study design. Publishing Group, 2002:695-716.

\section{Conclusion}

In patients with schizophrenia or schizoaffective disorder in the outpatient setting, risperidone reduced the risk of relapse more than haloperidol.

*See glossary.

$\nmid$ Information provided by author.

Source of funding:

Janssen Research

Foundation.

For correspondence:

Dr J G Csernansky,

Washington University

School of Medicine, St

Louis, MO, USA.

csernanj@

medicine.wustl.edu

\begin{tabular}{lcccc}
$\begin{array}{c}\text { Outcome over } \\
2.2 \text { years }\end{array}$ & Risperidone & Haloperidol & RRR (95\% CI) & NNT (CI) \\
\hline Risk of relapse & $34 \%$ & $60 \%$ & $48 \%(25$ to 64$)$ & $4(3$ to 7$)$ \\
\hline
\end{tabular}

$\ddagger$ Abbreviations defined in glossary; RRR, NNT, and Cl calculated from Cox proportional hazards data in article.

Most studies comparing typical with atypical antipsychotics are short term, have high rates of attrition, and use doses of haloperidol that may exaggerate the results of trials in favour of the atypical drug. ${ }^{1}$ The results of these deficiencies are that little is known about the long term effects of drugs that are often used for many years. The study by

Firstly, the study was done over a longer time period (median duration of risperidone treatment was 1 y) than is usually the case in trials of atypical antipsychotics. Secondly, the study considered patients already in remission. This is an important aspect because in practice atypical antipsychotics are frequently continued for relapse prevention. The positive finding in favour of risperidone is likely to improve confidence in its long term

The dose of haloperidol during the trial could be adjusted up to $20 \mathrm{mg}$ daily, although $63 \%$ of patients received $\leqslant 10 \mathrm{mg} /$ day and $37 \%$ received $15-20 \mathrm{mg} /$ day (mean modal daily dose $11.7 \mathrm{mg}$ ). Doses of haloperidol $>12 \mathrm{mg}$ are probably less well tolerated than lower doses. Trials allowing doses of haloperidol $>12 \mathrm{mg}$ may bias the results in favour of the atypical comparator, ${ }^{2}$ though some have argued that higher doses more accurately reflect clinical practice. Also, the trial excluded patients for a variety of reasons (eg, personality disorder, comorbid medical illness, and substance misuse). This limits the generalisability of the study findings and is likely to mean that any treatment benefits

Compared with some atypical antipsychotics, risperidone already had a stronger evidence base and clinicians have a great deal of experience in its use. The study by Csernansky et al adds considerably to this information by providing data on maintenance efficacy, although the results cannot be generalised to other atypical antipsychotics. Issues surrounding the comparator dose of typical antipsychotic drugs continue to be a concern and until trials can show the superiority of risperidone over optimal doses of haloperidol, doubt will remain in the findings because of the

Andrew M McIntosh, MB , ChB, MRCPsych University of Edinburgh Edinburgh, UK

1 McIntosh A, Lawrie S. Schizophrenia. In: Clinical Evidence. 6th issue. London: BMJ

2 Geddes J, Freemantle N, Harrison P, et al. Atypical antipsychotics in the treatment of schizophrenia: systematic overview and meta-regression analysis. BMJ 2000;321:1371-6. 